\title{
Investigation of Justice Sensitivity and its Relationship with Altruism among Undergraduates
}

\author{
Chunhua Shi ${ }^{1}$, Yan Huang ${ }^{1}$ and Baojun Wang ${ }^{2}$ \\ ${ }^{1}$ Institute of Applied Psychology, Hohai University, Nanjing 211100, China \\ ${ }^{2}$ Institute of the Earth Sciences and Engineering, Nanjing University, Nanjing 210046, China \\ ${ }^{*}$ Corresponding author
}

Keywords: Justice sensitivity; altruism; undergraduates; empirical investigation

Abstract. There has been a lot of research on justice sensitivity in psychology abroad, but it has just begun in China. 392 students from universities in Nanjing and Shanghai were measured by the Justice Sensitivity Inventory and the Self-report Altruism Scale. The results were as follows: (1) The level of justice sensitivity is relatively high, especially the perpetrator sensitivity and beneficiary sensitivity;(2)There are significant differences of gender, age, major, academic performance, appearance and family economic status in justice sensitivity;(3)Justice sensitivity is significantly related to altruism, the perpetrator sensitivity and the total score of justice sensitivity also positively predict altruism while the victim sensitivity negatively forecasts it. The finding's implications of psychology and policy were discussed, with emphasis on the reasons that there are many grouping differences in the justice sensitivity.

\section{Introduction}

Since the 1960s, the topic of justice has been brought into psychology, and the subjective experience of justice has acquired importance. The term justice sensitivity was put forward in 1995 although it hadn't been defined. By 2010, it was generally considered to be an independent, stable personality trait which has a cross-contextual, consistent individual difference. Justice sensitivity can be conceptualized as the ease of perceived injustice and the degree of reaction to the perceived injustice. It has four components, that is, the victim sensitivity, the observer sensitivity, the perpetrator sensitivity and the beneficiary sensitivity [1]. It was found in many researches that the victim sensitivity is mostly negatively correlated with prosocial behaviors while it is positively correlated with antisocial behaviors, the beneficiary sensitivity and observer sensitivity are mainly positively correlated with prosocial behaviors[2][3][4]. Although there have been many studies abroad, it has just begun in China. In particular, an empirical study of justice sensitivity on Chinese people is rare[5].

Therefore, it was aimed in this article to study the justice sensitivity of Chinese undergraduates and explore its relationship with altruism. The purpose was to provide the empirical evidence for cross-cultural research on justice sensitivity and enlightenment for the development of rational sense of justice among college students in China.

\section{Methods}

\subsection{Participants.}

The sample included 420 students from four universities in Nanjing and Shanghai in China. The valid sample size was 392 with males 217(55.4\%) and females 175(44.6\%); freshmen 53(39.0\%), sophomores 37(9.4\%), juniors $171(43.6 \%)$ and seniors 31(7.9\%); sciences 87(22.2\%), liberal arts 74(18.9\%) and engineering 231(58.9\%);the only child 251(64.0\%)and the non-only child 141 (36.0\%); self-rated excellent in academic performance 63(16.1\%), good 177(45.2\%), medium $117(29.8 \%)$ and below 35(8.9\%); self-rated excellent in looks 41(10.5\%), good 137(34.9\%), average 185(47.2\%) and below average 29(7.4\%); self-rated wealthy in family economy 10 (2.6\%), well off 79(20.2\%), average 207 (52.8\%), a little poor 86 (21.9\%) and poor 10 (2.6\%). 


\subsection{Measures.}

All the measures were administered and all the data were analyzed by the statistical software of SPSS 19.0.

The Justice Sensitivity Inventory [1]is a new version made by Schmitt. It includes four subscales (i.e. four kinds of justice sensitivity) with 40 items rated on 6 -point response format ranging from 0 to 5 . The higher the score, the higher the level of justice sensitivity. The scores of internal consistency reliability (Cronbach's alpha)were 0.89 0.94 in the current sample.

The Self-report Altruism Scale[6] is the most commonly used questionnaire to measure explicit altruistic behaviors, which consists of 20 items rated on 5-point response format with the range from 1 to 5. The higher the score, the higher the level of altruism. Cronbach's alpha was as high as 0.97 in this sample.

\section{Data Analysis}

\subsection{General situation of justice sensitivity.}

The order of four types of justice sensitivity was as follows: perpetrator sensitivity $(4.10 \pm 1.12)>$ beneficiary sensitivity $(3.65 \pm 1.00)>$ victim sensitivity $(3.48 \pm 0.96)>$ observer sensitivity $(3.17 \pm 1.04)$. The theoretical average of total score and the subscales is 2.5, the relatively higher level is 3.5. Using single-sample t-test, it was found that the total score of justice sensitivity, the perpetrator sensitivity and beneficiary sensitivity are significantly higher than the higher level respectively $(t=2.57, p=0.01 ; t=10.62$, $\mathrm{p}=0.00 ; \mathrm{t}=2.88, \mathrm{p}=0.00$ ); there is no significant difference between the victim sensitivity and the higher level $(\mathrm{t}=-0.49, \mathrm{p}=0.62)$; the observer sensitivity is significantly higher than the average level $(\mathrm{t}=12.84$, $\mathrm{p}=0.00)$.

\subsection{Grouping differences of justice sensitivity.}

By independent sample $t$ test, it was shown that females score higher in total score of justice sensitivity, the victim sensitivity and observer sensitivity than males $\mathrm{t}=2.66, \mathrm{p}=0.01 ; \mathrm{t}=2.38, \mathrm{p}=0.02 ; \mathrm{t}=2.26, \mathrm{p}=0.02$.

By one-way ANOVA of different majors, it was found that there is a significant difference in total score of justice sensitivity, there are also significant differences in the dimension of victim sensitivity, observer sensitivity and beneficiary sensitivity $F=16.61, F=22.93, F=23.12, F=9.39, p=0.00$. Through a post test (LSD), it was found that whether the total score or the dimension score, the level of liberal arts students' justice sensitivity is significantly higher than that of engineering students and science students $\mathrm{p}$ $=0.00$.

The freshmen and sophomores being merged into the lower grade group, the juniors and seniors into the higher grade group, by independent sample t test, it was shown that the difference between the higher grade students and the lower grade students is significant only in the victim sensitivity, that is to say, the higher grade students' level is relatively lower $\mathrm{t}=3.58, \mathrm{p}=0.00$.

In terms of whether it is an only child or not, by independent sample $t$ test, it was shown that there isn't significant difference in the total score of justice sensitivity and its dimensions $t=0.35 \sim 1.46$, $\mathrm{p}=0.73 \sim 0.15$.

Owing to the great difference of number of participants at the four levels of achievements self-assessment, the excellent and good students were merged into the better learning group, the middle and lower into the average learning group. By independent sample $t$ test, it was found that the victim sensitivity of the better learning group is significantly higher than that of the lower learning group $t=2.00$, $\mathrm{p}=0.04$, while the former is prominently lower than the latter in the perpetrator sensitivity $\mathrm{t}=-2.41$, $\mathrm{p}=0.02$.

Because the number of subjects with different self-evaluation of appearance differed greatly, those with excellent self-rated looks and low self-rated looks in this study were temporarily excluded. Among those with better looks and average looks, it was revealed that only in the beneficiary sensitivity, there exists a significant difference, that is to say, those with better looks score relatively higher $t=3.85, p=0.00$. 
Also because of the number of subjects at different levels is unbalanced, the subjects whose family economy was self-rated wealthy and well off were combined into the good economy group, the subjects whose family economy was self-rated relatively poor and poor were combined into the bad economy group. The self-rated average subjects were temporarily excluded in this study. By independent sample $t$ test, it was found that the good economy group is significantly higher than the bad economy group in terms of the total score and each dimension of justice sensitivity $t=6.80 \sim 12.79, p=0.00$.

\subsection{Correlation between justice sensitivity and altruism.}

By Pearson correlation analysis, it was found that all the dimensions and their total score are significantly correlated with altruistic behaviors except the victim sensitivity. The correlation coefficients ranging from large to small are $r=0.81$ (the perpetrator sensitivity), $r=0.64$ (the total score), $r=0.56$ (the beneficiary sensitivity) and $r=0.36$ (the observer sensitivity), $\mathrm{p}=0.00$. Stepwise regression analysis was conducted to further explore the influence of justice sensitivity on altruism. As shown in table1, the perpetrator sensitivity, the victim sensitivity and the total score come into the regression equation, the three variables account for $83.0 \%$ of the variance of altruism.

Table 1 Regression analysis of justice sensitivity to altruism

\begin{tabular}{lccccc}
\hline & $R^{2}$ & $\mathrm{~F}$ & $\mathrm{SE}$ & $\beta$ & $\mathrm{t}$ \\
\hline Perpetrator sensitivity & 0.78 & $635.72^{* * *}$ & 0.09 & 0.78 & $12.58^{* * *}$ \\
Victim sensitivity & 0.82 & & 0.11 & -0.57 & $-17.20^{* * *}$ \\
Total score of justice & 0.83 & & 0.05 & 0.79 & $19.29^{* * *}$ \\
$\quad$ sensitivity & & & & & \\
\hline Note: ${ }^{* * *}<0.001$. & & & &
\end{tabular}

\section{Discussion}

\subsection{General situation and characteristics of justice sensitivity among college students.}

It was found that the total score of justice sensitivity, the perpetrator sensitivity and the beneficiary sensitivity exceed the higher level, the victim sensitivity reaches a higher level, the observer sensitivity is higher than the middle level. All these results reflect probably there is a lot of injustice in the society and college students are very concerned about it. The levels of perpetrator sensitivity and beneficiary sensitivity are relatively higher, which indicates that college students are indeed restrained by morality or conscience, therefore their corresponding cognition, emotions and behaviors are regulated to ensure their social adaptation.

It was found in this study that the level of justice sensitivity of females is significantly higher than that of males, which is consistent with the relevant research abroad [2] [3], and inconsistent with the findings of Wang [5], in that no notable gender difference was found. The possible reason for the discordance lies in the different measuring tool used by Wang, that is a self-compiled questionnaire of justice sensitivity.

It was shown that the victim sensitivity level of seniors is significantly lower than that of juniors, which is consistent with foreign [2] [3] and domestic research [5]. It is suggested that with the increase of age, the individual's anxiety about being deprived by others decreases, which may lead to the emotional and social maturity and the reduction of victim sensitivity.

It was found that the beneficiary sensitivity of college students with better-looks is higher than that with average-looks, which is consistent with the study abroad [7]. The reason is that for those college students with better-looks the realization of their appearance advantage being useful for themselves to get help more easily will activate their feelings that they occupy unfairly more social resources and at the same time prevent others from acquiring social resources.

It was also found that there is a significant difference in justice sensitivity between college students with good economy and ones with bad economy. The same discovery was made by Wang, who found that the justice sensitivity of rural college students is higher than that of urban [7]. 


\subsection{The relationship between the justice sensitivity and altruism.}

In this study, it was found that the justice sensitivity excluding observer sensitivity, is positively correlated with altruistic behaviors, furthermore the perpetrator sensitivity and the total score can predict positively altruism whereas the victim sensitivity can forecast negatively altruism, which is consistent with the foreign researches [2][3][4].

\section{Summary}

The level of justice sensitivity is relatively high in Chinese undergraduates and the grouping differences exist in terms of gender, major, achievements, appearance, etc. Since different kinds of justice sensitivity have totally different impact on altruism, it is worthy of being considered by researchers, managers and government officials how to control the level of victim sensitivity while promoting the level of perpetrator sensitivity, observer sensitivity and beneficiary sensitivity.

\section{Acknowledgement}

This work was financially supported by General Project of Higher Education Teaching Reform in Jungian Province (2017JSJG088); Major Research Project of Higher Science Education Study by Professional Committee of China Higher Education Association of Science Education; Fundamental Research Funds for the Central University(Grand No.2017B606X14).

\section{References}

[1] M. Schmitt, A. Baumert, M. Gollwitzer, and J. Maes, The justice sensitivity inventory: Factorial validity, location in the personality facet space, demographic pattern, and normative data, Social Justice Research, vol.23, pp. 211-238, 2010.

[2] M. Gollwitzer, M. Schmitt, R.Schalke, J. Maes, and A. Baer, A symmetrical effects of justice sensitivity perspectives on pro-social and antisocial behaviour, Social Justice Research, vol.18, pp. 183-201, 2005.

[3] M. Howitzer, T. Rothmund, A. Pfeiffer, and C. Ensenbach, Why and when justice sensitivity leads to pro-and antisocial behaviour, Journal of Research in Personality, vol.43, pp. 999-1005, 2009.

[4] M. Gollwitzer, T. Rothmund, What exactly are victim-sensitive persons sensitive to?, Journal of research in personality, vol.45, pp. 448-455, 2011.

[5] Z. Wang, Y. Lv, J. Zhang, The justice sensitivity of college students and its relationship with parental rearing style, China Journal of health psychology, vol.24 24, pp. 1363-1369, 2016. In Chinese

[6] J. P. Ruthton, R. D. ChrisJohn, G. C. Fekken, The altruistic personality and the self-report altruism scale, Personality and individual differences, vol. 2, pp. 293-302, 1981.

[7] A. V. Hiel, D. D. Cremer, J. Stouten, The personality basis of justice: The five-factor model as an integrative model of personality and procedural fairness effects on cooperation, European Journal of Personality, vol. 22, pp. 519-539, 2008. 